\title{
The New Technology: The Consumer as Participant Rather Than Target Audience
}

\author{
R. CRAIG LEFEBVRE
}

\author{
Speaker: R. Craig Lefebvre, Ph.D., Population Services International \\ Moderator: James H. Lindenberger, Director, Center for Social \\ Marketing, College of Public Health, University of \\ South Florida
}

We need not to be let alone. We need to be really bothered once in a while.

How long is it since you were really bothered? About something important, about something real?

- Ray Bradbury

\section{Introduction}

New communication technologies and the emergence of what is being called "Web 2.0" are providing the opportunity for health promotion professionals to truly engage with their patients, customers, and audiences in ways unimaginable just a few years ago. Some of the more recent applications include: text messaging and mobile telephones for educational interventions to reduce sexually transmitted diseases among teenagers; interactive and entertaining health websites such as VERB and Whyville; sites where people with medical conditions can seek, give, and receive advice from other patients and healthcare providers (Organized Wisdom); and blogs of all descriptions hosted by health professionals, commercial entities, patients and advocates, and CEOs of healthcare organizations. Yet, these innovations have barely scratched the surface of the potential for these new technologies.

What is underappreciated by many social marketers who are beginning to experiment with these new technologies is that they are not simply new types 
of media with which to do the same old things. These new media signal a shift in thinking about how we communicate with our audiences. Even more alarming, in using these new media many marketers - commercial and social - continue to perpetuate the myth of the source-message-channel-receiver paradigm rather than embrace the collaborative and dynamic communication models these new technologies embody. While the reality has not changed, what these new technologies make plain is that it is, indeed, a networked world - one in which we do not design "messages" for priority audiences, stakeholders, partners, donors, and others groups, but a world in which they talk back to us, and just as importantly, with each other.

Social media facilitate collaborations and interactions among others. In its simplest forms, these media can be thought of as digital extensions of the interpersonal channels of promotion (the proliferation of word-of-mouth [WOM] and viral marketing campaigns in the commercial sector) and the narrowing of broadcast-type communication (slivercasting). However, thinking about these new media as simply new promotion channels to exploit misses the essence of what the new revolution is all about: using media in new ways NOT using new media. These new technologies have implications for how we think about the behaviors, products, and services we market; the incentives and costs we focus on; the opportunities we present; and places where we interact with our audience and allow them to try new things.

This article will elucidate how these new technologies, and social media in particular, can be used in our professional lives and in our health promotion programs. Several recent examples will be used to illustrate some of these applications. The implications of social media are not confined to who we develop our social marketing programs for, but the colleagues, information and inspiration sources, and resources we use to do our jobs bigger and better.

The development and diffusion of new media devices (cell phones, game boxes such as PlayStations and Wii, wireless digital assistants including Blackberries), the migration of other media to new delivery technologies (wireless, cable, satellite, and the Internet from print, telephone, television, and radio), new communication forms (IM, blogs, podcasts), the emergence of Web 2.0 businesses and the need to feed them all with all varieties of content continues to fracture the marketplace into finer segments. The portability of many of these new devices (iPods, Game Boys, PDAs) and the convergence of media content providers to these new devices (watch television shows, listen to radio or your MP3 files, and get news headlines on your cell phone) has been enabled not only by greater 
access to the Internet and wireless services, but greater access to broadband connectivity $24 / 7$.

Changes in communication technologies have immediate impacts on different elements of our audiences in ways that parallel the diffusion on any new innovation. However, the revolution in the Web 2.0 era is that these technologies are no longer "in a box" that people use: They are often open-access and allow users to interact with them and create new content themselves (blogs; podcasts; digital music, pictures and video mashups) and share this new content with others through sites such as Flickr and YouTube. Other services such as MySpace and FaceBook offer enhanced social networking opportunities among people with similar interests and goals. Indeed, Web 2.0 has come to refer to a second generation of services available on the Web that allow people to collaborate and share information online.

\section{What is Web 2.0?}

It is not places that people visit, but rather destinations where they go to get things done - Flickr and YouTube to share photos and videos, MySpace and Bolt2 to meet and network with people who share similar interests - whether they be hobbies, music, or dating. People demand active participation and sharing (Hof 2006). If we are to become involved in the Web 2.0 world for social marketing, we are required to understand and interact with it on its terms, not ours. Notions of sharing and collaboration are pretty rhetorical flourishes in presentations and publications; it is quite another thing when agencies contemplate whether to allow comments on their blogs and who can access their wikis or photo sites.

Levy and Stone (2006) note several other characteristics of this 2.0 world which we must consider:

- We can harness collective intelligence (it gets smarter the more you interact with it - think iGoogle searches, reader polls, Amazon's buyer suggestions, wikis, and the wisdom of crowds).

- We experience fewer barriers and have more opportunities to create and distribute user-, consumer- or audience-generated content (AGC) - from Craigslist to YouTube and Revver to ads for the Chevy Tahoe.

- We can organize the content ourselves (tagging with del.icio.us) rather than fit into existing taxonomies.

- Websites are no longer favored for their fortress-like qualities; the more connected to others - and to us - the better (RSS feeds, permalinks, mashups).

- We no longer have to be satisfied with reaching audiences, but can now enable entire communities. 
- We confront the blurring of boundaries between creators and audiences - and who decides which is which.

\section{All Media is Social: The Cluetrain Manifesto}

The appearance of the Cluetrain Manifesto in 1998 marked the emergence and definition of the web as an audience-centric force. Although the earliest years of the development of the Internet envisioned a digital world of democracy, in practice the web had, by most accounts and appearances, become a space where technological prowess, top-down planning, closed systems, and money (both for development of sites and access) had become predominating themes. The Manifesto, a set of 95 theses, challenged this status quo and has, directly or indirectly, refueled the search and development for making the web the social tool it is becoming. It also clearly stated that the audience was in control. Here are just a few of the statements that stand behind the audience as content creator movement.

- Markets are conversations.

- The Internet is enabling conversations among human beings that were simply not possible in the era of mass media.

- These networked conversations are enabling powerful new forms of social organization and knowledge exchange to emerge.

- In just a few more years, the sound of mission statements and brochures - will seem as contrived and artificial as the language of the 18th century French court.

- Even at its worst, our newfound conversation is more interesting than most trade shows, more entertaining than any TV sitcom, and certainly more true-to-life than the corporate websites we've been seeing.

\section{What's Social About Behavior?}

An important point to reiterate about the new media world is that it is a networked one, not unidirectional or linear. This reality does not just pertain to how we depict our communication processes; it also reflects people's reality. A cursory look at some of the health behaviors that are the focus of social marketing programs reinforces the fact that all health behaviors are, to a greater or lesser degree, social. New media now allows people to explore these social aspects with greater freedom than ever before. Freedom from geographic and temporal boundaries, open access to sources and information, and the ability to create the digital and social contours that surround health conversations, information seeking, decision making, and behavioral choices. 
Encouraging screening behaviors for conditions and diseases that don't present immediate symptoms has been the subject of much work since at least the 1950s when the Health Belief Model (HBM) emerged as a way to conceptualize the process for tuberculosis screening. Over the years, HBM and other individual models of screening behavior have predominated much of our thinking despite the evidence that social influences are likely much more important. Whether my healthcare professional recommends that I get screened for high blood pressure or blood cholesterol levels, breast, cervical, skin or prostate cancer, or other potential (and silent) problems is a social communication process - not simply a perception of perceived risk and severity of the disease. Indeed, whether I know other people who have been screened for the condition, what their experiences were, and whether they suggest that I should be screened too, are much more powerful influences on my decision making than some theorists would have us believe. That it is possible to sit down with my desktop, laptop or smart phone, connect to the Internet and find like-minded others who want to share their experiences, can have a tremendous impact on how social my treatment-seeking behavioral determinants become. The web is changing the weights in our models of determinants of health behavior.

The same types of issues hold true for other health behaviors. Consider the man who is trying to make lifestyle modifications that might include diet modifications or increasing his level of physical activity. How is the decision to make such changes arrived at - in isolation in front of a mirror or lying in bed in the morning? How does he decide how to begin to prepare for or address the problem? What are some of the stronger sources for motivation and inspiration? Where does the reinforcement for positive changes usually come from? Where does he go when he feels a weak moment or frustration with his progress? How does he celebrate success?

I venture to say that in at least $80 \%$ of all cases the answer to these questions is "other people." The key question for social marketing programs is not just what behaviors to focus on, how to create incentives, reduce barriers, open up more opportunities to try and sustain behaviors, and then to promote them, but it is answering the "who" question. Not just the relatively simple one of "who is the credible source of information," or the more complex one of "how do we change social norms and acceptability," but the audience-centric one: With whom does he interact on a daily or weekly basis as part of his daily routines and is influential in the choices he makes about health behaviors?

The same types of questions are also important when we address 1) the cessation of addictive behaviors - where social support becomes such an important 
determinant of short-term and long-term success; 2) compliance with medical regimens - where friends and family caregivers play a huge role; 3) precaution adoption - taking actions or changing behaviors to avoid or reduce the threat of intentional and unintentional injuries; 4) health information seeking - where over $66 \%$ of online searches involve looking for other people's opinions, reading blogs, visiting social network sites; and 5) taking collective action and advocacy where the rise of mobile technologies have taken these activities to a whole new level of sophistication and effectiveness (see Smart Mobs).

\section{Social Network Interventions}

When we accept the fact that we are working with health behaviors that occur within the frame of a social reality, as opposed to the all-American individualistic reality, the power of the new media as a social network tool - not just another channel through which to direct messages in the "old world" manner - becomes clear. When we accept the world as networked, and not layered or hierarchical, the role of any individual within a social system becomes much more flexible and nuanced. Not all people will be equally comfortable in the many different roles offered by the networked world. Seekers, curators, connectors, mavens, lurkers, conveners, weavers, guides, and many other types of roles are now possible for us to take on, encourage, or support in our social marketing programs.

Some of the questions we should be asking ourselves as social marketers in the networked world are:

- How can we enhance linkages that already exist among people, organizations, and communities to allow them to access, exchange, utilize, and leverage the knowledge and resources of the others?

- How do we help develop, nurture, and sustain new types of linkages that bring together like-minded people, mission-focused organizations, and communities that share interests to address common problems and achieve positive health and social change?

- How do we identify, encourage and enable the many different types of indigenous helpers that are found in social networks so that they can be more effective in promoting health?

- What do we do to better engage communities in monitoring, problem analysis, and problem solving; striving to health and social equity; and increasing social capital?

- How do we go about weaving together existing social networks of individuals, organizations, and communities to create new sources of power and inspiration to address health and social issues? 
- How does a networked view of the world disrupt our usual ways of thinking about and engaging the people, organizations, and communities with which we usually work? What are the insights we can gain from this perspective?

\section{The Social Media Ecosystem}

The social media ecosystem is undergoing rapid development, change, and refinement. One of the mantras in some quarters of this world is "life is perpetual beta" meaning that the old world practice of developing, testing, tweaking, retesting, and finally launching programs, products, and services has been replaced by the on-the-fly idea that no system or process will ever be perfect. In fact, the best way to improve programs, products, and services is to bring them to the marketplace and let the user/audience comment, hack, provide feedback, and even write copy. In our practices of social marketing, the same old world ideology persists - despite protestations that we are audience-focused. Formative testing, when it occurs, is most often done in formal, contrived situations that set out to "solicit input and feedback" from the audience - NOT engage them in the development and implementation of the program itself as participatory models of public health espouse. Imagine, then, the reaction when we suggest putting them in charge of the process and letting them sit in the creative director's chair. Experiments in the commercial sector with consumers designing and shooting advertisements to be shown during the Super Bowl (the ultimate advertising show place) would make most senior managers in the public and voluntary sector reach for a drug of choice if floated as a proposal for their programs. Why? Higher levels of transparency and accountability may be part of the rhetoric, but I suggest the reality is that we don't trust real people to solve their problems or have insights into how to do it. Allowing the audience to be not just at the center of the social marketing process, but co-create the programs and even control them is, for most of us and the organizations we work for and on behalf of, a very disruptive idea.

This notion of how disruptive the idea really is quickly becomes apparent in talking about the adoption of new media tools for a program or organization. Consider the "problems" with blogs, a relatively benign format. What do we do about people commenting on our site? What if they say bad things? And, how do we turn the comments off? In short, how do we eliminate risk and avoid facing the truth? How do we continue doing things the safe and comfortable way? In the world of networks, connections, and instant communication that can be accessed by anyone, anywhere, anytime, the answer is simple - you can't. But that won't keep people from trying. 
Wikis, the backbone of new knowledge management systems from the US Central Intelligence Agency to open communities around the world (Wikipedia being the most visible example), demand the questions: How do we control the content? What if someone changes things? Who decides what is in or out? Can we limit access? While there is a (small) case to be made for having answers to these questions, don't let that case overshadow the key issue: People and organizations are threatened by the idea of opening themselves up to being the non-experts, a mere part of the conversation (as opposed to the directors and choreographers of it), and to being the recipients of communications - not the source. What people and organizations who try to play in this new world with their old rules discover is that the networked world is also not a very forgiving place.

Communication, engagement, transparency, and trust are the four pillars for working in the new media world. If you and your organization can't bring those to the table, it will not be long before the rest of us figure it out, confront you, and challenge you. If however, you view new media tools (blogs, podcasts, wikis, social network sites, text and multimedia messaging) as complementary to traditional communication activities and recognize the social characteristics of effective communication, then you have a better-then-average chance of succeeding and making new friends and allies in your quest to achieve public health and social change.

\section{What is User-Generated Content?}

Once you have accepted, if not mastered, the Zen of Web 2.0, you are ready to face your biggest challenge: people formerly known as the audience. This phrase embodies the radical shift in perspective with which all professionals in the marketing and communication professions are grappling - the audience is in charge of what they look at and listen to, and if they don't like what you have, they'll just make their own or find someone else's. User generated content can be anything text, audio, video, categories or ranks, social networks - and the list continues to expand as technology companies continue to push the envelope and the people continue to play with them. Here are a few facts about how pervasive this trend of the $\mathrm{C}$ (Content) Generation is becoming (Pew Internet and American Life Project, 2006):

- Among adults, $35 \%$ of Internet users have created content and posted it online;

- $8 \%$ of Internet users keep a blog;

- $14 \%$ work on their own webpage;

- $13 \%$ create or work on webpages for others; 
$26 \%$ share something online that they created themselves, such as artwork, photos, stories, or videos.

When we expand the definition of usergenerated content beyond productionintensive work, we find that in addition to this core group of $\mathrm{C}$ generators we have:

- $34 \%$ of people who have used the Internet to share and display photos or get photos developed;

$30 \%$ of Internet users that have rated a product, service, or person using an online rating system;

- 18\% who have taken material found online and remixed into a new creation (mashups);

- $11 \%$ of adults 18 and older who have used online social or professional networking sites.

Finally, let's take a look at the "prevalence figures," as our epidemiologist friends would intone:

- MySpace was the most popular website in July 2006-60 million members. If it were a country, the population of MySpace would be the ninth largest in the world, behind Mexico;

- 1.167 billion videos were downloaded from YouTube in January 2007 (54.7 million unique visitors/month);

- Technorati counts over 71 million blogs;

- Sprint Nextel cell phone subscribers share 30 million photos, play 2 million games and access 1 billion webpages - a month;

- Verizon led all wireless carriers in September 2006 with 5 billion text messages and 100 million multimedia services (MMS) sent by subscribers during the month.

The numbers just keep on increasing. And we keep on watching, and not acting. And before we know it, we will be (or maybe some of us already are) in the connected world, where newspapers not only have an online presence, but feature social media as part of their audience engagement strategies. Already, national security and intelligence is collected, distributed, and analyzed through blogs and wikis; political campaigns flourish and are decimated by what appears on YouTube; and the President of CBS News wants to assure its viewers that they will be able to watch the Evening News wherever they are with whatever device they want - even "God forbid, sitting at home watching the television." 
Content generated by people, not audiences, is not a new idea; new technologies just make it more accessible and ubiquitous than ever before. What is new, however, is that people's expectation to be involved and to have a voice is changing. If we do not give them one in our social marketing programs, they will tune us out and go somewhere else.

The lesson and power of AGC was brought home to me recently on a visit to the University of British Columbia's Museum of Anthropology, featuring a special exhibit on the Chewa People - "The Village is Tilting." The exhibit presented pictures and the costumes that have been developed by these people in Malawi to incorporate HIV/AIDS education into their story-telling dancing. $\mathrm{HIV} / \mathrm{AIDS}$ has been devastating these people - "tilting the village" - and the Chewa use elements of Gule Wamkulu itself - dance, drama, dialogue, and humor - to strip away conventional images of AIDS to reveal its inextricable links to an interconnected set of conditions and causes: poverty, gender inequality, and civil injustice. The local people developed this "intervention" themselves, without the aid of specialists in "entertainment education" or other Western methods. The expression of content, how and when it is presented, and by whom is completely self-determined. And the curators of the museum simply "discovered" it.

Today, many different types of communities are creating their own responses to the tilting they see in their worlds. The web and other digital technologies give them new methods to create and express their stories, distribute them and make access more open and available to people across the globe. My question is, how can social marketing help them do it better and with broader impact?

\section{Implications for Social Marketers}

The worlds of social media, Web 2.0, mobile marketing, and digital technologies are changing every week, if not every month. In the two months since this presentation was made at the 11th Annual ISM conference in Baltimore, the constant hum is about the introduction of the iPhone. Two months ago, we weren't even aware such a product was coming online. Statistics I used in a presentation six months ago, especially those related to the prevalence and use of these technologies, seem like ancient history when used today. The overriding response I get from people who sit in on sessions about these new media, whether they are seasoned social marketers or graduate students, is summed up by the comment of one of my students: I feel like a dinosaur. If 20-somethings in public health feel like dinosaurs in this new world, we have serious challenges to confront before social marketing and many public health practices become irrelevant. 
What I suggest as first steps in responding to this world and effectively engaging with it are:

Be Everywhere. The idea of media multiplexity, using multiple channels and technologies in our programs, is paramount. In the networked and connected worlds, mobile phones may be more important than television for some audiences, podcasts less relevant than radio, print magazines irrelevant to users of RSS readers. But looking for "the magic bullet" is not where the commercial marketing is focused. Instead, ubiquity is the new exclusivity.

Interactivity and AGC. The offering of more, not some, occasions for our audiences to become people, collaborators, and directors must be built into our program development philosophies and practices. This means moving beyond coalition meetings and focus group rooms and embracing people as idea generators, strategists, and producers. A finding from the Edelman Trust Barometer Studies, that people trust information coming from people like themselves not scientists, CEOs, or celebrities - goes to the point that elitist notions of message delivery need to be dumped. Whether people shop for shoes, electronic devices, books, hospitals, or solutions to health problems, what they look for is information from their peers - not from us, the "experts."

Collaboration and Sharing. This philosophy will have a substantial impact on not just how we think about the people formerly known as the audience, but how we collaborate with our colleagues, partners, and competitors. When public health and social marketers learn how to harness and utilize our collective wisdom through things like social marketing wikis, we can unleash talent, apply wisdom, and be more efficient stewards of the program resources we have to address the health and social issues we face.

Social Networks and Social Capital. These new technologies also bring us to a new appreciation for the study of social networks and social capital. Somewhat intangible ideas now come alive on the web every moment of everyday. We can no longer ignore them. I believe that incorporating these two concepts into the core of what we do as social marketers is also one of our great challenges to improve our effectiveness and relevance in the next decade. Social media allows us ways to operationalize these concepts and create interventions to directly impact them. Inputs and outputs now become observable, tangible events, not the whispers and presumptions of interpersonal communication and group dynamics we have had to cope with in the past.

Aggregate or Centers of Gravity (COGs). The concept of "the long tail" (Anderson 2006) brings the commercial implications of the web to life by suggesting that although numbers will accumulate to a few - the COGs like 
Amazon, MySpace and Yahoo! - the space for many different groups to occupy niches or segments of the tail is wide open and more accessible than ever before. One response to this observation is to try identifying "our" spaces on the long tails of health and social improvement. Another strategy is to search for the spaces others have already staked out. When you embrace the ideas I've been describing here, the choice is obvious.

Education, Engagement, Entertainment, Empowerment, and Evangelism. Finally, I propose that there are 5 Es we need to keep in mind as we work in this new world, whether the work is enabled by the "old" technologies or the latest ones. Again, it is not the technologies we use in our programs that need to change, but our frames for looking at the world and thinking about what we do. In designing interventions that will effectively lead to behavior change, we have to ask ourselves: 1) Do we harness the ability to educate people about issues and problems that are relevant to them (not us); 2) Is what we do engaging them in positive and meaningful ways; 3 ) Is there an entertainment value to our offerings; 4) Do people believe and feel empowered as a result of their experiences with our programs (products and services); and 5) Do we take advantage of every opportunity to let our customers and clients become our evangelists? If we fail to do all five, we are failing them and ourselves. And failure in our work is not an option.

\section{About the Author}

R. Craig Lefebvre is Chief Maven of Population Services International, Washington, DC.

\section{References}

ANDERSON, C. 2006. The long tail: Why the future of business is selling more of less. New York: Hyperion.

HOF, R. 2006. Web 2.0 has corporate America spinning. Business Week, June 5.

LENHART, A., J. HORRIGAN, and D. FALLOWS. 2004. Content creation online: $44 \%$ of U.S. Internet users have contributed their thoughts and their files to the online world. Pew Internet \& American Life Project., Washington, DC. http://www.pewinternet.org/pdfs/PIP_Content_ Creation_Report.pdf (accessed July 17, 2007).

LEVY, S., and B. STONE. 2006. The new wisdom of the web. Nerwsweek, April 3.

LOCKE, C., R. LEVINE, D. SEARLS, and D. WEINBERGER. 2001. The Cluetrain Manifesto: The end of business as usual. New York: Basic Books. 